REVISTA DE ESTUDOS EM ARTES CÊNICAS

E-ISSN 2358.6958

\title{
O método Suzuki precede uma filosofia
}

\author{
Luciana Espírito Santo Brandão \\ Bruna Emanuele Fernandes
}

Para citar este artigo:

BRANDÃO, Luciana Espírito Santo; FERNANDES, Bruna Emanuele. O método Suzuki precede uma filosofia. Urdimento - Revista de Estudos em Artes Cênicas, Florianópolis, v. 3, n. 42, dez. 2021.

doi DOI: http:/dx.doi.org/10.5965/1414573103422021e0106

Este artigo passou pelo Plagiarism Detection Software | iThenticate 
Luciana Espírito Santo Brandão²

Bruna Emanuele Fernandes ${ }^{3}$

\begin{abstract}
Resumo
O presente artigo tem por propósito apresentar o contexto cênico e histórico que antecede e acompanha o início da carreira do diretor japonês Tadashi Suzuki, bem como expor sinteticamente princípios técnicos e teóricos que definem sua noção sobre encenação. Partindo de sua biografia, desde a infância no contexto pósSegunda Guerra Mundial até seus primeiros anos como diretor profissional, buscamos expor a combinação de aspectos dos teatros oriental e ocidental que levaram ao desenvolvimento do método Suzuki. Por fim, a partir de escritos do próprio diretor, intentamos um resumo sobre sua visão técnica e teórica sobre a atuação.
\end{abstract}

Palavras-chave: Teatro contemporâneo oriental. Método Suzuki. Treinamento para atores. Tadashi Suzuki. SCOT Company.

\title{
The Suzuki method precedes a philosophy
}

\begin{abstract}
The aim of this article is to present a scenic and historical context that precedes and follows the beginning of the career of Japanese director Tadashi Suzuki, as well as synthetically exposing technical and theoretical principles that define his notion of staging. Starting from his biography, from childhood in the post-World War II context to his early years as a professional director, we seek to expose the combination of aspects of Eastern and Western theaters that led to the development of the Suzuki method. Finally, based on the director's own writings, we intend to summarize his technical and theoretical vision of acting.
\end{abstract}

Keywords: Contemporary Japanese theater. Suzuki method. Training for actors. Tadashi Suzuki. SCOT Company.

${ }^{1}$ O presente artigo deriva da dissertação de mestrado em Artes da Cena intitulada Os métodos Viewpoints e Suzuki em interface à composição visual, defendida em 2018 por Luciana Espírito Santo Brandão junto ao Programa de Pós-Graduação em Artes da Escola de Belas Artes da Universidade Federal de Minas Gerais (PPG-Artes/EBA-UFMG).

2 Mestrado em Artes pela Escola de Belas Artes da Universidade Federal de Minas Gerais (UFMG-2018). Graduação em Artes Plásticas pela Escola Guignard (UFMG-2013). Formação de atriz no Centro de Formação Artística e Tecnológica (CEFART), da Fundação Clóvis Salgado (2010). luciana.es.brandao@gmail.com

\section{(9) http://lattes.cnpq.br/5470404475211051 (iD https://orcid.org/0000-0002-5997-4446}

${ }^{3}$ Mestrado em Artes (2022) na Escola de Belas Artes (EBA) da Universidade Federal de Minas Gerais (UFMG 2022). Bacharel em Letras com ênfase em Estudos de Edição pela Faculdade de Letras (UFMG). maripousar@gmail.com 


\section{El método Suzuki precede a una filosofía}

\section{Resumen}

El propósito de este artículo es presentar el contexto escénico e histórico que precede y sigue al inicio de la carrera del director japonés Tadashi Suzuki, así como exponer sintéticamente los principios técnicos y teóricos que definen su noción de puesta en escena. A partir de su biografía, desde la infancia en el contexto posterior a la Segunda Guerra Mundial hasta sus primeros años como director profesional, buscamos exponer la combinación de aspectos de los teatros oriental y occidental que llevaron al desarrollo del método Suzuki. Finalmente, partiendo de los escritos del propio director, pretendemos resumir su visión técnica y teórica de la actuación.

Palabras-clave: Teatro oriental contemporáneo. Método Suzuki. Formación de actores. Tadashi Suzuki. Compañía SCOT. 


\section{Introdução}

Figura 1 - Tadashi Suzuki

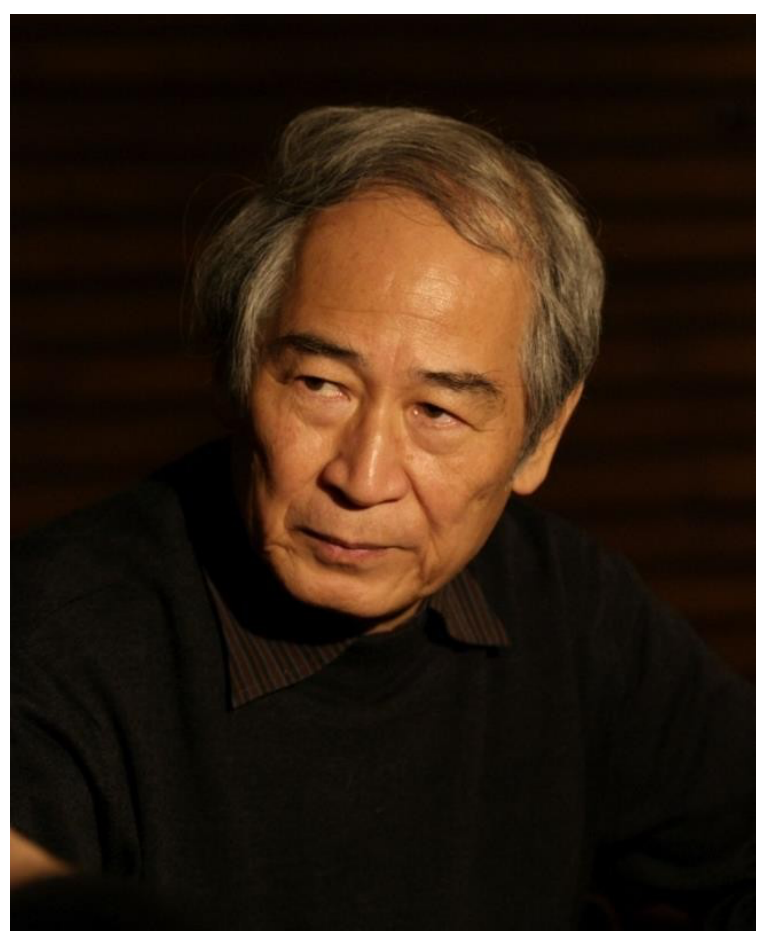

Fonte: Lisa Govan/Arquivo SCOT

O método Suzuki é uma prática de treinamento desenvolvida pelo encenador japonês Tadashi Suzuki (1939-), aplicada em sua companhia SCOT (Suzuki Company of Toga) e disseminada, através de intercâmbios internacionais, por todo o mundo. A principal questão de Suzuki no treinamento em questão é "restaurar o corpo humano na sua unidade total"4 (Suzuki, 2015, p. 65), para o evento da performance, e descobrir as expressões únicas e inatas do ator, e, assim, restabelecer as energias animais e orgânicas do corpo que, por ação da cultura de uma sociedade, foram diluídas e não mais utilizadas na sua plenitude. A diluição da prontidão do corpo pela cultura pode ser entendida, neste contexto, onde as sensibilidades perceptivas e expressivas do corpo humano são utilizadas por completo onde elas fornecem meios básicos de comunicação. Seu rigoroso

${ }^{4}$ restore the wholeness of the human body in performance. (Tradução nossa) 
treinamento físico e vocal disciplina o ator para a consciência e o controle da sua respiração, bem como para a noção e o uso do centro de gravidade, dos pés, da coluna, das tensões necessárias e desnecessárias em seu corpo.

O treinamento de Tadashi Suzuki evoca um senso ético no fazer teatral, encarnando o corpo do ator como pilar de análise e treinamento para sua produção artística. Contudo, não há muita informação disponível em português sobre Tadashi Suzuki, apesar de ele estar vivo. Sua biografia é ainda pouco estudada, uma vez que sua obra e seu método são mais amplamente discutidos em livros como o de Paul Allain ${ }^{5}$ e de autoria do próprio Suzuki. Isto torna difícil para nós a compreensão sobre de que maneira teria surgido um diretor tão inovador para a cultura japonesa. Assim, a seguir, discorreremos sobre o contexto do teatro tradicional japonês e a transição para o teatro moderno Shingeki. Além disso, traremos uma breve biografia de Tadashi Suzuki, seu início da carreira artística e reconhecimento mundial, bem como a contextualização de sua estética.

\section{Suzuki: o método e o artista}

Afora os textos publicados em sites e livros de Suzuki, usou-se como fontes para a pesquisa que deu origem a este artigo os estudos fundamentais de Paul Allain, Akihiko Sanda, James Brandon. Contudo, destaca-se aqui a enorme importância, para a produção deste texto, do autor Yukiriho Goto. Atualmente professor da Universidade de São Francisco, nos Estados Unidos, sua tese para doutoramento em Filosofia, Drama e Teatro, defendida em 1988 junto à Universidade do Havaí, intitulada Tadashi Suzuki Innovator of Contemporary Japanese Theatre, serve como fonte para todas as(os) autoras(es) que se dedicam a tornar pública a genialidade e a importância do diretor japonês.

A pesquisadora Juliana Monteiro, em sua dissertação de mestrado, por exemplo, também utiliza Goto como fonte. Ao perceber que o próprio Paul Allain constantemente fazia referências ao trabalho de Goto, Luciana Brandão, primeira coautora deste texto, pesquisou seus escritos e descobriu seus artigos e tese. 
Devido à dificuldade de se encontrar, no Brasil, esta última, ela entrou em contato com o autor, que gentilmente indicou como obtê-la. Além da tese, utilizamo-nos também do artigo "The Theatrical Fusion of Tadashi Suzuki", escrito em 1989. Devido ao fato de ser tão difícil ter acesso aos escritos de Goto, consideramos pertinente trazer aqui algumas citações mais extensas deles, uma vez que discorrem, com riqueza de detalhes históricos e conceituais, sobre a trajetória artística do diretor Tadashi Suzuki.

Os teatros Nô e Kabuki são as duas formas principais do teatro japonês, para o qual o foco de fruição são o corpo e o trabalho do ator, mais do que qualquer outro aspecto da expressão artística em questão. Em linhas gerais, uma vez que não é este o foco de concentração de nosso estudo, alguns fatos e características do teatro Nô, dentre outros, são: sua origem data do século XIV; ele surgiu da combinação do artista Kan'ami e seu filho Zeami; teve alta influência no Zen Budismo; sua estética se caracterizava por refinamento, elegância e simplicidade (Goto, 1988).

Com ritmo lento, a encenação era feita apenas por atores homens, e a linguagem era simbólica e alusiva, cheia de metáforas, com música tocada sempre por três percussionistas e um flautista, movimentos estilizados e de dança, além da notável característica do uso de máscaras. Tratava-se de uma dança fundamentada na música, através da qual se fazia expressa a emoção contida nos versos do canto, acompanhada de uma orquestração (Giroux, 1991). Zeami (13631441?), filho do ator Kan'Ami (1333-1384?), começou a treinar para ser ator aos 7 anos de idade.

No tratado Fûshikaden, "Da transmissão da flor de Interpretação”, escrito por Zeami, ele contextualiza, dentre outros aspectos fundamentais sobre atuação no teatro Nô, o conceito de flor, importante para compreender a estética de Suzuki. Tal conceito se caracteriza enquanto

O efeito cênico da representação de Nô. Ou melhor, o efeito emocional por ela provocado, graças ao trabalho do ator. [...] A flor não é outra coisa senão o insólito que sente o espectador, ou seja, a flor é a imagem do Belo que suscita o sentimento do espectador através da linguagem de representação. [...] A flor se encontra na disposição do espírito; e a 
semente deve ser o ofício (Giroux, 1991, p.105-106).

É apenas através de treinamento que se é possível conquistar a flor.

O próprio diretor Tadashi Suzuki, em seu livro The Way of Acting, sinaliza que o teatro Nô possui quatro características que o tornam únicos, sendo elas: 1) A predominância do uso de energia animal desde o processo de ensaio à apresentação. Utilizando uma quantidade mínima de eletricidade para iluminar o teatro, todo o modo de produção remonta a uma prática pré-moderna de arte; 2) A segunda característica diz respeito ao universo narrativo do teatro Nô: as obras são sempre expressões não realistas. Partindo de sonhos e visões, a estrutura das peças no teatro Nô evocam "este mundo que consiste no que não pode ser visto ou ouvido na vida cotidiana, apenas o que pode ser sentido, absorvido" (Suzuki, 1986, p.30);‘ 3) A característica, segundo Tadashi Suzuki, diz respeito a uma rigorosa estrutura que prevê, inclusive, todo o ambiente em que a obra será encenada. "É seguro dizer que, quando o teatro Nô é encenado, está no palco criado para ele. $\mathrm{Na}$ verdade, esse palco em si constitui um elemento importante em toda a arte" (Suzuki, 1986, p.30-31); 4) por fim, a quarta e última característica apontada por Suzuki a respeito do teatro Nô envolve a natureza da performance Nô: mesmo que um ator Nô, no meio de seu papel, caia morto no palco, a performance continua. Sua descendência direta de algumas práticas religiosas tradicionais dá ao teatro Nô o mesmo status de não poder ser interrompido independente do que aconteça com seus participantes.

Já o teatro Kabuki data do século XVII, em 1603. Em um primeiro momento, permitia mulheres em cena, como foi o caso da atriz Okemi, que realizavam danças instigantes e sensuais. Contudo, elas acabaram sendo banidas da prática ainda no século XVII, em 1629. Ao interpretar papéis femininos, os atores homens eram chamados de onnagata.

As semelhanças entre os teatros Kabuki e Nô podem ser descritas como

${ }^{6}$ this world consists of what cannot be seen or heard in everyday life, only what can be felt, absorbed. (Tradução nossa)

7 it is safe to say that when Nô is enacted, it is on the stage created for it. Indeed, that stage itself constitutes an important element in the whole art. (Tradução nossa) 
sendo o fato de encenarem peças muito estilizadas com convenções determinadas que caracterizavam cada uma, bem como a presença de música integrada a dança, fala e movimento. Já em contraste, o teatro Kabuki inova ao ter peças mais dinâmicas, com mais vitalidade e ação. O cenário, o figurino e a maquiagem possuíam uma beleza espetacular (Goto, 1988).

Em 1868, o Japão sofreu um processo de ocidentalização característica da Modernidade, e os intelectuais da época passaram a achar os teatros Nô e Kabuki expressões antiquadas e ultrapassadas. À época, eles estavam deveras interessados em algo mais próximo dos moldes europeus. Assim, surgiu o movimento Shingeki (Teatro Novo), cujo grande expoente foi Osanai Kaoru (18811928). Em 1909, ele fundou o Jiyû Gikijô ${ }^{8}$ (Palco Livre), um grupo especializado na tradução de peças ocidentais como Ibsen e Chekhov, ou em peças originais cuja estética fosse aproximada da europeia.

Figura 2 - Osanai Kaoru (1881-1928)

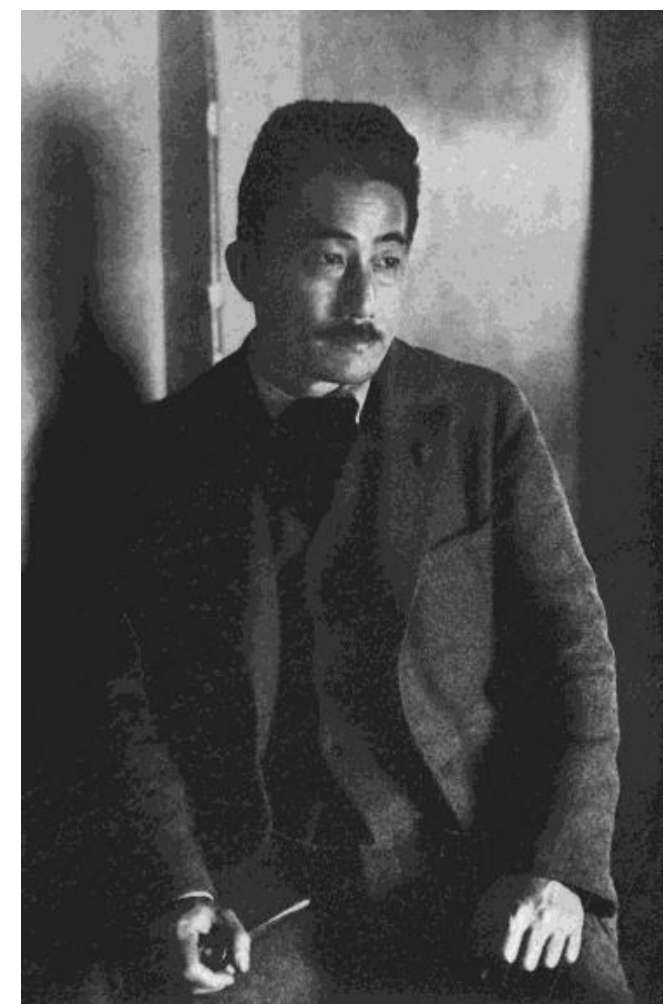

Fonte: Autor desconhecido/Imagem fornecida pela Biblioteca Nacional Diet, Japão

${ }^{8}$ A maior parte das fontes sobre o assunto faz a tradução do termo japonês em inglês. Por coerência de idioma, aqui traduziremos os termos em inglês do original em japonês. Por isso, em traduções norteamericanas, veremos que se tratava do movimento Free Stage. 
Em certo momento, para garantir a qualidade e a adesão a esse tipo de teatro, apenas peças em termos ocidentais modernos poderiam ser produzidas, segundo determinação de Kaoru. Assim, era inevitável que os métodos de encenação de maior uso europeu chegassem ao Japão. O realismo russo e o sistema Stanislavski aparecem na ilha nipônica em 1919, fazendo com que, em poucos anos, o status quo da encenação fosse aos moldes do método Stanislavski do teatro de Moscou. Por isso, até a década de 1960, por quarenta anos, o movimento Shingeki esteve em alta. Suas características são, conforme se verifica nos escritos do autor Yukihiro Goto, resumíveis no que três companhias - o teatro Bungakuza (Literário), o teatro Hauyûza (do Ator) e teatro Mingei (de Arte Popular) - desenvolveram, sendo elas:

1) Teatro realista;

2) Encenação em teatros que tenham o proscênio em arco;

3) Completa subordinação ao texto e às ideias do dramaturgo;

4) Conviç̧ão de ser um teatro de formação, em que se transmitiam os valores, exemplos e as questões sociais do mundo moderno.

Contudo, a adesão do público foi baixa, pois apenas classes intelectualizadas estavam a par das ideias ocidentais e, por isso, podiam desfrutar do conteúdo das peças. A partir da década de 1960, os jovens artistas se opuseram ao movimento e buscaram alternativas à estética Shingeki. Na década de 1970, o movimento de teatro experimental já era conhecido como Movimento Shôgekijô undô (do Pequeno Teatro). ${ }^{9}$ Kara Jûrô (1940-), por exemplo, com seu grupo Jôkyô Gekijô (Teatro da Situação), foi o diretor responsável por sair do proscênio em arco, estabelecendo uma relação íntima e de comunhão entre ator e plateia.

9 Goto, em uma nota de rodapé, alerta que o termo exato para a vanguarda teatral dos anos 1960 e 1970 é impreciso. Há também o tempo angura, cuja conotação está mais próxima do "underground", Shôgekijô, em português, "Pequeno Teatro", também fora usado, pois agrupa o movimento pelos pequenos teatros em que se apresentavam do final das décadas de 1960 e 1970. Termos como "pós-shingeki" e "anti-shingeki" também foram usados (Goto, 1988). 


\section{A infância do mestre}

E é nesse contexto artístico que surge o diretor Tadashi Suzuki. Conforme consta na tese de Yukiriho Goto, Suzuki nasceu em 20 de junho de 1939 em Shimizu, Japão, e é o terceiro filho de uma família de vendedores de madeira. Seu avô paterno era músico entoador de gidaiyû, um estilo musical narrativo usado no teatro de bonecos clássico (bunraku). Seu pai era um homem à moda antiga, que vivia como um samurai e era muito devoto da doutrina budista (Goto, 1988). ${ }^{10}$

Sobre a infância do diretor, Goto considera importante dizer, e aqui o reiteramos, que quando criança Suzuki já demonstrava sinais de liderança, como ao organizar todas as crianças do bairro para construírem uma casa para brincar no alto de uma colina, ou ao fazer com que todos juntos saíssem para observar as estrelas no céu. Na trajetória de um diretor que levaria a si e aos membros de sua companhia para o interior do país, onde construíram um complexo teatral em uma antiga fazenda, perceber tais traços desde sua infância torna possível compreender melhor o artista de que estamos falando.

Em casa, Suzuki diz ter vivido uma criação política e culturalmente muito heterogênea, em que um irmão se dedicava a ouvir música clássica ocidental em um lado da casa, e em outro ponto o pai ouvia músicas de devoção militar, ou o avô entoava gidaiyû. Finalmente, é importante contextualizar que Suzuki nasceu apenas seis anos antes do fim da Segunda Guerra Mundial, quando seu país sofreu com os ataques de bombas atômicas em Nagasaki e Hiroshima. Crescer em um país devastado e acompanhar todo o período de recuperação deu a Suzuki outro senso de percepção da humanidade (Goto, 1988).

Em abril de 1958, aos 19 anos, Tadashi Suzuki inicia, na Universidade de Waseda, em Tóquio, o curso de Ciências Políticas e Econômicas. Imediatamente, entra para o clube de teatro da universidade, o Waseda Palco Livre (WPL), em cujo âmbito frequentemente se produziam peças de um autor que Suzuki muito leu na adolescência: Anton Tchekhov. O grupo WPL, Suzuki mais tarde soube, era na verdade um grupo dedicado ao estudo marxista, afiliado ao Partido Comunista

${ }^{10}$ Chama atenção a falta de informações sobre a mãe de Tadashi Suzuki - reflexo este da cultura e da sociedade japonesa. 
Japonês, que interpretava teatro russo realista aos moldes do sistema de Stanislavski.

\section{Formação artística versus contexto político}

Durante a década de 1960, o maior problema social do Japão girava em torno do tratado mútuo de segurança entre Japão (perdedor da Segunda Guerra Mundial) e Estados Unidos (vencedor), assinado após a rendição nipônica em 1951, em que se previa submissão japonesa aos estadunidenses. Em 1960, o tratado foi renegociado, e, ao invés de ter sua plena autonomia devolvida, graças à tensão mundial provocada pela Guerra Fria, o Japão manteve o apoio dos Estados Unidos, declarando-se, assim, do lado do capitalismo, em oposição à Rússia e ao comunismo.

Ora, se o Waseda Palco Livre era marxista, pró-Rússia, evidentemente era contrário à soberania norte-americana. Segundo afirma Goto, Suzuki foi um adolescente tímido e de poucas palavras, mas que participou ativamente nas reuniões e nos debates dentro do grupo. O WPL possuía uma agenda que ia além da produção teatral, de resistência política à situação nacional. Suzuki, ao perceber que a atividade cênica ia sendo deixada de lado, afastou-se do grupo. Por estar mais engajado com o fazer artístico do que com a militância política, a classe artística o isolou e o considerou um apolítico, sendo ele alvo de muitas críticas.

Em sua passagem no WPL, Suzuki tornou-se membro do setor de direção em 1959, após participar de uma montagem como ator e perceber a falta de talento e compreensão sobre o que era exigido para um ator performer. Entre 1959 e 1960, inicia sua carreira como diretor, e apesar de, depois, sair da WPL, Tadashi Suzuki chegou a conquistar a posição de diretor principal e a ser responsável por cinco produções.

Sob a presidência de Suzuki (1960-1961), o foco da WPL se direcionou a suas atividades artísticas, em vez de a assuntos políticos. Em um simpósio na primavera de 1960, Suzuki anunciou a nova direção do clube, dizendo "O teatro estudantil deve ser ideologicamente artístico" e que "voltaremos a peças que abraçam firmemente a subjetividade do homem" (q. In Kan, Sengo 162). De fato, a "subjetividade do homem" deve continuar sendo uma das principais preocupações do diretor, figurando 
como um tema básico a reaparecer na maioria de seus principais trabalhos (Goto, 1988, p.30). ${ }^{11}$

Uma das produções que merece destaque aqui é a obra Room for Rent (de maio de 1960), que, apesar de não ter sido um sucesso, foi importante para a carreira de Suzuki, como aponta Goto, pois foi por ocasião dela que se iniciou a parceria dele com o amigo e dramaturgo Betsuyaku Minoru (1937-). Foi com Betsuyaku e junto a doze outros atores que Suzuki, ao sair, por razões políticas, da WPL, fundou sua própria companhia, a Palco Livre ${ }^{12}(\mathrm{PL})$. Naquele momento,

Do ponto de vista artístico, o desejo de Suzuki de começar sua própria companhia era, em certo sentido, um ato desafiando o movimento Shingeki. Durante o início da década de 1960, muitos jovens artistas da geração pós-guerra expressaram seu descontentamento contra Shingeki, o gênero principal do teatro japonês moderno. Para eles, a tradição teatral realista/naturalista de Shingeki parecia mundana e previsível. [...] O diretor fez seus sentimentos sobre Shingeki muito claros quando o denunciou em 1962, ano após a fundação de seu grupo: "Shingeki é muitas vezes dito como chato. Certamente, eu concordo. Na verdade, eu quase não quero ver peças de Shingeki. A razão é simples. Shingeki não possui imaginação e novos talentos que possam fazer uso irrestrito do japonês. Além disso, aqueles que têm talento real nunca sonharão em trabalhar no estilo feudal de Shingeki" (Goto, 1988, p.39-40). ${ }^{13}$

Em março de 1966, a trupe de Suzuki reorganizou e mudou seu nome para Waseda Pequeno Teatro (WPT). Este é o nome sob o qual o trabalho de Suzuki se tornou mundialmente famoso, pois foi com essa trupe que o diretor se apresentou no Festival de Teatro das Nações, em Paris, em 1972. A partir desse festival, o

${ }^{11}$ Under Suzuki's chairmanship (1960-1961), the WFS emphasized its artistic activities rathes than political affairs. At a symposium in spring 1960, Suzuki announced the club's new direction: 'A students theater must be ideologically artistic', and 'we are going back to plays that firmly embrace man's internal situation' (qtd. In: Kan, Sengo 162). In fact, 'man's internal situation' was to remain one of Suzuki's main concerns, a basic theme reappearing in most of his major works. (Tradução nossa)

12 Free Stage, nas traduções em inglês.

${ }^{13}$ From an artistic viewpoint, Suzuki's desire to start his own acting troupe was in a sense an act in defiance of the shingeli establishment. During the early 1960s many young artists of the postwar generation voiced their discontent against shingeki, the mainstream genre of modern Japanese theater. To them, shingeki's realistic/naturalist theatrical tradition appeared mundane and predictable. [...] The director made his feelings about shingeki very clear when he denounced shingeki in 1962, the year following the foundation of his troupe: 'Shingeki is often said to be boring. Certainly, I agree. In fact, I hardly want to see shingeki plays. The reason is simple. Singeki lacks rich imagination and new talent who can make an unconstrained use of Japanese. Besides, those who have real talent would never dream of working in the feudalistic colonies of shingeki”. (Tradução nossa) 
trabalho de Suzuki ficou conhecido, sobretudo por o compararem com o diretor polonês J. Grotowski, dando-lhe, inclusive, a denominação de "Grotowski japonês" (Beeman; Kadogami; Suzuki, 1981). Sobre a comparação, Suzuki comentou:

Eu fui chamado de "Grotowski japonês" em Paris, mas na verdade, meu trabalho é muito diferente do dele. Grotowski abandonou a "palavra" muito bem. Eu já trabalhei dentro de um contexto japonês para revitalizar a palavra japonesa e ajudar os atores a levarem a palavra ao corpo. 0 caminho de Grotowski para incentivar a independência do corpo sem a palavra é muito estreita no final. Eu considero a palavra dentro do corpo. Desta forma, há uma correspondência entre nós dois (Beeman; Kadogami; Suzuki, 1981, p.89)..$^{14}$

\section{Conexão entre tradição e contemporaneidade}

Segundo Goto, Suzuki descobriu a profundidade da tradição teatral japonesa quando testemunhou a performance Nô de Kanze Hisao no Festival de Teatro das Nações, em Paris, no ano 1972. No festival, Suzuki fez duas importantes descobertas que depois influenciaram suas atividades artísticas. Uma delas foi a nova ideia que ele teve para o design arquitetônico de um teatro. O festival ocorreu no Teatro Recamier, anteriormente uma casa residencial, que o diretor Jean-Louis Barrault convertera temporariamente em um teatro.

Suzuki viu várias performances nessa caixa cênica pouco ortodoxa, concebendo a ideia de "fazer uso de um espaço onde pessoas de fato viveram, um espaço preenchido com uma história de uso humano recente" (Suzuki, 1984, p. 116 apud Suzuki, 1986, p. 70). ${ }^{15}$ Essa ideia foi realizada em 1976, quando Suzuki e a companhia WPT se mudaram para a vila Toga-mura, no Japão, onde eles converteram uma fazenda entre as montanhas em um complexo teatral. ${ }^{16}$

Já a segunda das descobertas de Suzuki, por ocasião do já citado festival, foi

\footnotetext{
${ }^{14}$ I have been called 'The Japanese Grotowskl' in Paris, but really, my work is much different than his. Grotowski has abandoned the 'word' to too great an extent. I have been working within a Japanese frame to revitalize the Japanese word and help actors to take the word into the body. Grotowski's drive to encourage independence of the body without the word is far too narrow in the end. I contain the word within the body. In this way there is a correspondence between the two. (Tradução nossa)

15 conceived the idea of "making use of a space where people had actually lived, a space filled with a history of actual human use. (Tradução nossa)

${ }^{16}$ Este tema será melhor abordado, neste texto, mais adiante.
} 
sua percepção da rica tradição das artes performáticas japonesas, particularmente a Nô. No festival, o prestigiado ator Nô Kanse Hisao apresentou um fragmento de Dyogi Temple em um palco distinto ao que é próprio do teatro Nô.

Eu sempre havia visto performances do Nô à maneira tradicional, agora, vendo uma apresentação sob circunstâncias tão incomuns, tive de reconhecer a sua soberania teatral. O rigoroso treinamento que condicionou e formou o corpo do ator produzia uma brilhante força e presença no palco, precisamente nos menores detalhes do movimento. A máscara e o figurino que eu tão bem conhecia brilhavam na nova luz. [O teatro] Nô em Paris era magnífico, o público estava enfeitiçado. Pela primeira vez comecei a compreender o que Zeami quis dizer quando ele falava da yûgen, ou "stilness"'17 [estado de permanência], em uma nova performance, ou a imagem além da visão (Suzuki 1984, p. 114 apud Goto, 1989, p. 105). ${ }^{18}$

Figura - Típico teatro Nô - Theater Noh Prefektur Ishikawa (Nogakudo) -, Indonésia

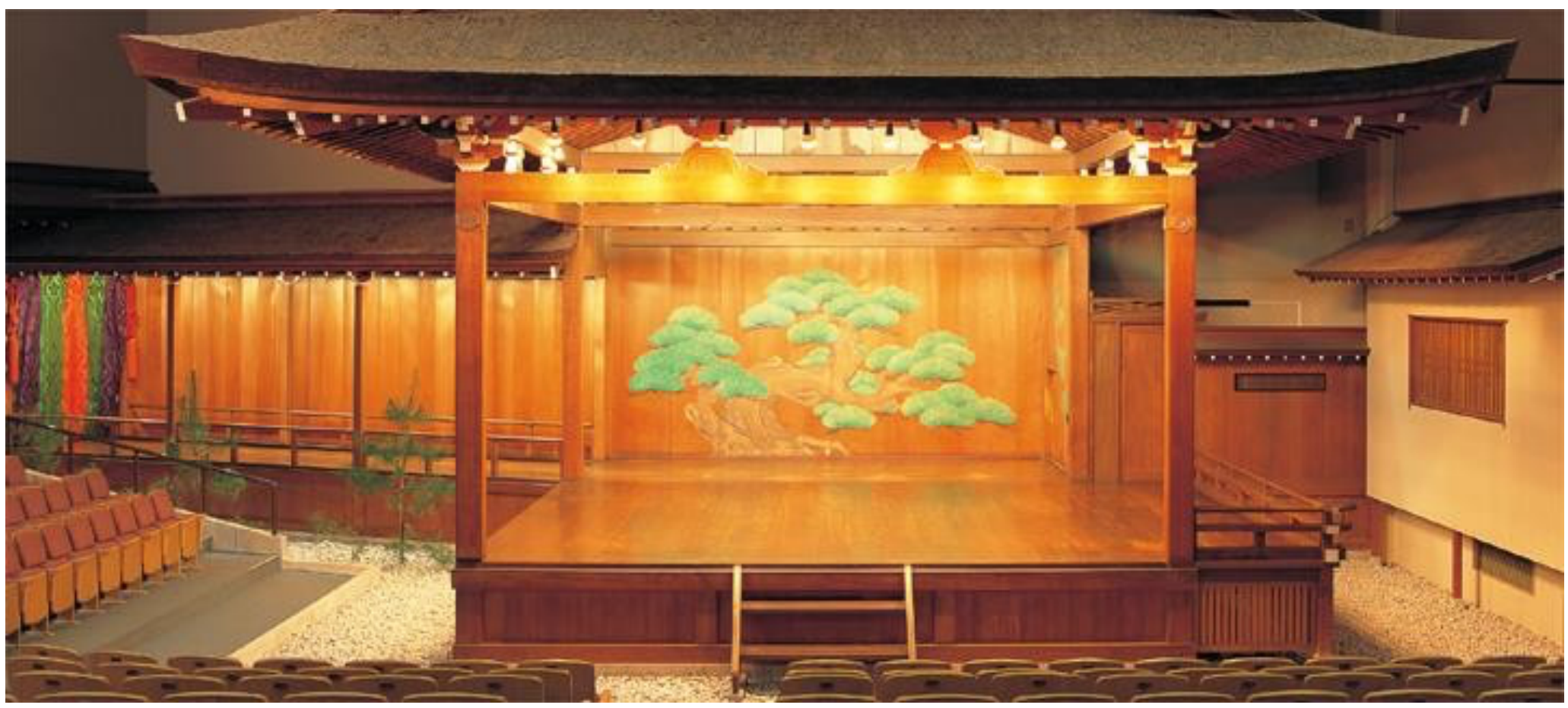

Fonte: Domínio público

17 Um dos preceitos de Zeami é "mover o espírito aos dez décimos, mover o corpo aos sete décimos" (Giroux, 1991, p.128).

18 I had always seen no performed in the traditional way; now watching a performance under these unusual circumstances, I was made to recog- nize its superb theatricality. The rigorous training that had tempered and shaped the body of the actor produced a brilliant liveliness on the stage, right down to the tiniest details of movement. The masks and costumes I knew so well sparkled in a new light. Nô in Paris was superb; the spec- tators were bewitched. For the first time I began to realize what Zeami meant when he spoke of yzigen, of stillness in a performance, or of the vision beyond sight. (Tradução nossa) 


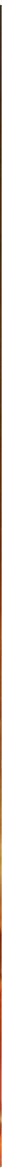

Fonte: JPD

Portanto, como podemos ver nas fotografias acima (figuras 3 e 4), o espaço físico que acolhe o espetáculo Nô com as convenções que the são particulares, bem como o palco em que o espetáculo ocorreu exigiram do ator Kanse Hisao que potencializasse sua performance para vencer as adversidades espaciais. Para Suzuki, que antes fora um severo crítico do teatro tradicional Nô, pelo fato de nele as encenações se darem sempre da mesma forma como determinado há centenas de anos, tal performance causou um êxtase.

Ali, frente a todas as dificuldades, Suzuki pôde verificar o que séculos de configuração e composição estética, via treinamento, eram capazes de fazer com as potências de energia e presença cênicas em um ator. Assim, se em 1971 Suzuki criticava as artes Nô e Kabuki, agora, testemunhando o poder da tradição através da performance Nô, apresentada de maneira tão pouco convencional, ele modifica 
essa visão crítica. O que Suzuki descobriu foi que "seguir as regras não é a única maneira de garantir uma boa performance. Quando uma tradição consegue ser quebrada com sucesso, a profundidade do Nô consegue se tornar mais aparente" (Suzuki, 1984, p.115 apud Suzuki, 1986, p.72). ${ }^{19}$ Essa experiência no exterior deu ao diretor a possibilidade de revitalizar técnicas e atitudes dentro do contexto do teatro contemporâneo. Isso se tornaria a grande essência da estética do método Suzuki, que se mantém até os dias atuais (Goto, 1989, p.105).

Inspirado pela combinação entre os teatros ocidental e oriental, ao retornar de Paris, Suzuki passa a buscar integrar a expressividade tradicional dentro de peças ocidentais. Seu primeiro e mais relevante trabalho dessa forma de experimentação foi a adaptação da peça As troianas, de Eurípedes, em 1974.

Segundo Goto, o desejo de Suzuki não é simplesmente retornar para as tradições do Nô e do Kabuki, mas reintroduzir um pouco da sua essência conceitual no teatro contemporâneo (Goto, 1989, p.105). Assim, almeja preencher a lacuna entre o teatro tradicional e o teatro moderno no Japão, bem como estabelecer uma nova forma contemporânea, que vai dar um "efeito social que transcende apenas o teatro, causando impacto em outras áreas artísticas" (Suzuki apud Goto, 1989, p. 92). ${ }^{20}$

Para que o desenvolvimento do método Suzuki se desse, o diretor contou com o trabalho muito importante de uma das atrizes que dirigia, Shiraishi Kayoko (1941-). Foi observando Kayoko que Suzuki percebeu que, se tirarmos do corpo os vícios e as obsolescências que a tecnologia provoca na vida contemporânea, era possível descobrir sensibilidade e força corpóreas em nível ancestral. A ideia da consciência física, própria do teatro clássico japonês, levou Suzuki a afirmar que o verdadeiro sentido da linguagem teatral não é o que o dramaturgo escreve, mas a fisicalidade do ator. A palavra, portanto, não é o que determina a expressão física do ator, mas suas sensações corporais e psicológicas resultam na verdadeira expressão da palavra (Goto, 1988, p.178).

19 following the rules is not the only way to ensure a great performance. When a tradition can be successfully broken, the profundities of the no can become all the more apparent. (Tradução nossa)

20 a social effect which extends beyond the theatre itself, giving it an impact on other cultural areas. (Tradução nossa) 


\section{Toga-mura}

Como mencionado, Tadashi Suzuki e sua companhia Waseda Pequeno Teatro fizeram uma mudança radical apenas dez anos após a sua fundação: em 1976, a companhia saiu da sede em Tóquio e migrou para Toga-mura, em Toyama, a 360 quilômetros da capital japonesa. A companhia já havia consolidado sua obra mais icônica, a montagem de As troianas (ou Trojan Woman), em 1974, e alcançado notoriedade nacional e internacional. À época, Tadashi Suzuki recorda que:

Nossa decisão de realocar não foi pretendida como uma fuga secreta para buscas egocêntricas e esotéricas, mas sim como uma declaração pública desafiadora criticando a centralização social e cultural no país ao redor da capital (Suzuki, 2015, p.86). ${ }^{21}$

Suzuki e sua companhia foram questionados na época pela mídia local, que não compreendia por que uma companhia em seu melhor momento se afastaria do centro de Tóquio, onde todo o capital cultural e financeiro do país se concentrava. Contudo, é valioso perceber que o que orientou a companhia a assumir tal decisão foi a busca por afirmar uma visão política, crítica e artística não apenas no discurso das obras, mas da própria maneira de estar no mundo. Tadashi Suzuki, a essa altura, via-se como um crítico ao processo acelerado de globalização e de concentração de renda em Tóquio e percebia esse processo como algo que prejudicava sua concepção sobre teatro.

A partir da instalação da companhia em Toga-mura, seu nome foi modificado de Waseda Pequeno Teatro para SCOT (sigla para Suzuki Company of Toga). Assim, a mudança era algo natural à trajetória que o grupo estava construindo para si. Sobre a mudança da companhia, o mestre disse que:

Na verdade, o motivo pelo qual acabamos em Toga foi mais ou menos o mesmo motivo pelo qual, anos antes, estabelecemos o WPT no segundo andar de um café em Tóquio. Não porque o espaço do café se encaixasse em nossa imagem ideal de um teatro de caixa preta com cem lugares,

${ }^{21}$ Our decision to relocate was not intended as a secret escape into egocentric, esoteric pursuits, but reather as a defiant public statement criticizing the social and cultural centralization on the country around the capital. (Tradução nossa) 
mas sim porque nos deu a oportunidade de dar mais um passo, por menor que fosse, em direção aos nossos ideais artísticos (Suzuki, 2015, p.86). ${ }^{22}$

É interessante observar, nesse processo, que à primeira vista é possível criar uma idealização e romantização em torno da louvável e corajosa decisão por sair do segundo andar de um café em Tóquio para ocupar instalações de uma fazenda ao estilo tradicional japonês em meio a um parque natural em uma vila de, atualmente, pouco mais de mil habitantes. Contudo, mais do que por sua deduzida excentricidade, tal feito é visto pela companhia e por Tadashi Suzuki como algo natural às buscas artísticas do grupo.

Em busca de uma forma de concretizar minha visão artística, rejeitei essas tendências, determinado a encontrar uma forma de produzir meu trabalho sem sacrificar meus ideais, e assim fundei a empresa Waseda Shôgekijô [WPT]. Com este grupo, pude criar um lugar onde artistas que compartilhavam desse mesmo ponto de vista crítico, até mesmo desafiador, sobre a sociedade pudessem trabalhar independentemente das estruturas das companhias de teatro dominantes da época, sem comprometer seus princípios (Suzuki, 2015, p.87). ${ }^{23}$

Como um artista que buscava uma simbiose entre noções corporais das artes cênicas tradicionais de sua cultura em associação a questões contemporâneas a si, ocupar um espaço rural e natural trazia ao modus operandi da companhia o que a sua estética defendia.

Para intensificar nossa perspectiva marginal, tínhamos que torná-la 0 mais dinâmica possível e ver aonde isso nos levaria artisticamente. Ao vir para Toga, um lugar que não poderia ser mais descentralizado de Tóquio, fui capaz de criar do ponto de vista talvez mais extremamente marginal disponível, profundamente influenciado pelos desafios diários de viver em tal lugar (Suzuki, 2015, p.87).

${ }^{22}$ In fact, the reason we ended up in toga was more or less the same reason that, years earlier, we established the Waseda Shôgekijô on the second floor of a Tokyo café. It was not because the café space fit our ideal image of a one-hundred-seat black box theater, but rather because it gave us the opportunity to take one more step, however small, toward our artistic ideals. (Tradução nossa)

${ }^{23}$ Searching for a way to realize my artistic vision, I rejected those trends, determined to find a way to produce my work without sacrificing my ideals and thus founded the Waseda Shôgekijô company. With this group, I was able to creat a place where artists who shared this same critical, even defiant, point of view on society could work independently of the dominant theater company structures of the time without compromising their principles. (Tradução nossa) 


\section{Uma ponte para as Américas}

Sandford Robbins, atual diretor de produção artística da Universidade de Delaware, contou, em palestra durante o simpósio "Transformation Trough Training", na Universidade de Skidmore, em Saratoga Springs, que ele foi o primeiro norte-americano a ter contato com o treinamento do método Suzuki. Em 1978, e por iniciativa de Robbins, Tadashi Suzuki iniciou seu programa de treinamento para artistas ocidentais. Das primeiras turmas de artistas e estudantes de teatro a participar dos cursos de verão em Toga-mura, saíram os atores da SITI Company, que formariam a companhia em 1992, junto a Anne Bogart.24

\section{Um fundamento teórico e técnico para atuação}

Ao longo de quase sessenta anos de carreira artística e de mais de cinquenta como diretor da SCOT, Tadashi Suzuki pôde, ao longo de sua trajetória, desenvolver um senso próprio sobre o trabalho de ator, seja no campo teórico da encenação, seja no de sua prática através do tempo. Tanto em seu site quanto em experiências presenciais com o seu método de treinamento, são disponibilizados alguns textos que são fornecidos como base de seu pensamento artístico, como os intitulados "Um fundamento técnico e teórico de atuação", "Cultura é o corpo" e "A lacuna nos métodos de treinamento".

Como forma de avançar rumo a uma conclusão para o presente artigo, serão por nós expostos aspectos que compõem os fundamentos técnico e teórico de atuação desenvolvidos pelo diretor Tadashi Suzuki. Em diversas fontes publicadas no site da companhia, bem como em livros de autoria do diretor, há textos e artigos por meio dos quais podem ser conhecidas suas visões política, social, filosófica e estética, que constituem a base de seu pensamento. No presente artigo, abordaremos brevemente a necessidade de um ponto de vista para se atuar, a presença do outro como espectador, a percepção do corpo invisível, o corpo animal e o stilness (estado de permanência).

${ }^{24}$ Disponível em: <https://www.youtube.com/watch?v=l91eYpTq33g\&t=915s>. Acesso em: 19 fev. 2018. 
A concepção da atuação como uma forma de linguagem é trazida por Tadashi Suzuki como o resultado de uma investigação por ele empreendida sobre o comportamento humano e suas relações. A exposição metafórica de como a sociedade se manifesta é transmitida pela performance do ator quando esta se encontra impulsionada pelo desejo de fazer com que outros reavaliem o mundo que conhecem e percebam um novo, seja de maneira coletiva ou individual.

Assim, seja para seu próprio bem ou para o bem de um grupo particular, o ator encarna a palavra escrita via uma exploração física e vocal que segue um conjunto específico de regras. Caso esse esforço seja bemsucedido através do compartilhamento de um ponto de vista único do texto escrito para muitas pessoas, nós o chamamos de atuação (Suzuki, 2021, [s.p.]). ${ }^{25}$

Se através da atuação é possível investigar metáforas sobre comportamentos humanos em sociedade transmitidos a um conjunto de pessoas, ao qual denominamos plateia, a apresentação desse comportamento humano carece de um ponto de vista. Quais seriam as motivações para que um diretor japonês, tendo crescido em um país vencido na Segunda Guerra Mundial após o lançamento de duas bombas atômicas, realizasse na década de 1970 a montagem de As troianas? Seja para a adaptação de uma obra dramatúrgica com mais de 2.000 anos, seja para a produção de uma dramaturgia original em 2021, Suzuki pontua a necessidade de se pautar as motivações artísticas da encenação sob o desejo de comunicar através do corpo e da voz/palavra uma perspectiva particular comumente pactuada entre toda a equipe envolvida em tal produção artística.

Em última análise, a atuação é igualmente derivada de um desenvolvimento da avaliação e/ou da percepção da sociedade (que é artificial, ainda que orgânica e única), uma constante epifania que semeia luz em como e por que nós escolhemos as relações que temos com um grupo particular ou com indivíduos (Suzuki, [s.d.], [s.p.]). ${ }^{26}$

25 Thus, either for their own sake or on behalf of a particular group, the actor incarnates the written word via a physical and vocal exploration that follows a specific set of rules. If this effort succeeds in sharing a unique point of view on the written text with many people, we call it acting. (Tradução nossa)

${ }^{26}$ Ultimately, acting is derived from a similarly developed evaluation/awareness of society that is both artificial yet organic and unique -an ongoing epiphany that sheds light on how and why we choose the relationships we have with particular individuals and group. (Tradução nossa) 
Para que essa constante epifania se dê, a apresentação de um ponto de vista artístico sobre determinado tema cênico não basta: há que se ter o destinatário da informação, a presença do "outro". Graças ao ato de consciência de que seu corpo está sendo observado, o ator imediatamente se coloca em estado de presença e passa a ser capaz de utilizar sua energia animal para fins de comunicação de um ponto de vista. Segundo Suzuki, ainda que durante a encenação não seja possível ver quem o observa, o ator consegue sentir que alguém o vê e ouve.

Assim que percebe que está sendo visto, os atores desenvolvem um desejo por comunicar seu ponto de vista. Contudo, para que o desejo de comunicação se concretize, o ator deve, segundo a concepção suzukiana de encenação, dominar sua produção de energia animal e consciência do que o diretor chama de corpo invisivel. Energia animal e corpo invisível são conceitos distintos e complementares, e para melhor compreendê-los, o texto "Cultura é o corpo" de Suzuki, publicado em 1984 na revista Performing Arts Journal, elucida a questão, frente à qual o diretor parte de um alerta sobre a diferença entre uma sociedade culta e uma sociedade tecnologicamente avançada.

A sociedade tecnologicamente avançada seria aquela que substitui o uso de energia animal para o uso de energia não animal. Energia animal é aquela gerada exclusivamente pelo corpo humano, assim como acontece em tração animal por meio de bois e cavalos, por exemplo; já a energia não animal é a derivada de fontes não animais, como o petróleo, a eletricidade, energia nuclear, eólica etc. O principal aspecto da crítica e da análise de Suzuki é que o desenvolvimento tecnológico, a partir de energia não animal, afasta o corpo humano da necessidade de sobrevivência. Por exemplo: não é necessário correr para garantir o alimento, caçando um animal, pois temos supermercados que nos fornecem alimentos. Não necessitamos exclusivamente de relações sexuais entre nossos corpos para procriarmos, pois há hoje a possibilidade da fertilização in vitro. Não necessitamos que nosso deslocamento seja feito pelas nossas pernas, pois existe, desde o surgimento da roda, suportes mecânicos que, surgidos de nosso desejo de fazer mais pelo corpo, tornam desnecessário seu uso para seu próprio deslocamento.

Toda esta substituição de energia animal por energia não animal torna o 
corpo obsoleto, sobretudo no que concerne a sua capacidade de produção de energia animal. Certamente, Tadashi Suzuki não defende que devamos abrir mão de todo e qualquer avanço tecnológico, mas nos alerta sobre como o desejo de ampliar nossas capacidades motoras e sensitivas - como as de ver, ouvir, comunicar, deslocar etc. - distancia nosso corpo de sua própria capacidade de realização dessas percepções e ações.

Paralelamente, para o ator - e, neste caso, é possível incluir todo tipo de performer que se expresse artisticamente por meio do corpo -, há a preocupação sobre como recuperar o corpo como gerador de energia animal, pois é nele que reside, segundo a concepção de Suzuki, toda força e capacidade expressivas. Mas do que seria feita essa energia animal?

O corpo humano tem certas necessidades essenciais que devem ser atendidas para sustentar a vida. Uma criança pode sobreviver sem qualquer tipo de consciência corporal, mas depende de ajuda dos outros. Mesmo que seu coração bata automaticamente, ele ainda precisa de comida. Para que o bebê se torne independente, deve se apoiar conscientemente nas principais funções físicas necessárias para atingir suas necessidades diárias, sendo as mais importantes: produção de energia; calibração do ar; controle de centro de gravidade (Suzuki; Steele, 2015, p.57). ${ }^{27}$

Como energia, oxigênio e gravidade não são visíveis a olho nu, embora facilmente percebidos, Suzuki os sinaliza como base para o que ele chama de corpo invisível. Frente a uma sociedade cujos valores são voltados para variações de energia não animal, a relação corporal consciente que proporciona maiores domínio e controle sobre a produção de energia, respiração e gravidade se torna um ato de resistência contra o corpo contemporâneo, amparado por tecnologias. E basta que algum desses eixos do corpo invisível entre em crise para que toda a sua sobrevivência esteja comprometida.

Quanto mais energia o corpo produz, de mais oxigênio ele precisa, o que

${ }^{27}$ The human body has certain essential needs that must be met to support life. An infant can survive without any kind of body awareness, but it depends heavily on the help of others. Even though its heart beats automatically, it still needs food. For the infant become independent, it must learn to consciously control the key physical functions required to achieve its daily needs, the most important of which are: enerdy production; breath calibration; center of gravity control. (Tradução nossa) 
por sua vez intensifica sua respiração. Quando a respiração se intensifica, ela desafia o equilíbrio do corpo, ou o controle de seu centro de gravidade. O treinamento existe, então, não só para desenvolver essas capacidades de forma independente, mas também para aprofundar sua inter-relação. Quanto mais estivermos aptos para expandir o fluxo no processo de produção de energia, pegando energia para manter nosso equilíbrio com nosso centro de gravidade, mais variedade de movimento nos será possível, aumentando a nossa estabilidade e sustentabilidade na vida. Essencialmente os mesmos princípios podem ser aplicados na atuação (Suzuki; Steele, 2015, p.60). ${ }^{28}$

Logo, além de ter mais controle sobre cada eixo de produção de energia animal, um corpo, ao dominar sua manipulação, tem sua capacidade de se sustentar vivo, e, portanto, expressivo, aumentada consideravelmente. Performar com domínio faz com que um corpo esteja vivo e desperto. Por exemplo: respirando-se melhor, faz-se com que soe mais potente uma voz, uma vez que a presença de mais ar dentro dos pulmões permite a enunciação de longas frases com poucas inspirações. Dominar a produção de energia e equilíbrio torna o corpo mais forte e veloz, capaz de realizar melhor movimentos e deslocamentos pelo palco.

Por isso, a demanda pela concentração é crucial no método Suzuki, uma vez que a técnica provoca, em quem a põe em prática, situações limítrofes de resistência muscular, de equilíbrio e respiratórias. Tais limites, uma vez tensionados, vão ao encontro do acesso ao corpo invisível, que trabalha com a respiração, a energia e o equilíbrio do corpo. Resgatar comandos que automatizamos e tornamos obsoletos em suas capacidades plenas invoca um processo quase catártico. Quem sou eu, o que é o meu corpo? O que meu corpo é capaz de fazer? O que me custa estar aqui em nome do teatro? O que é fazer parte do evento teatral?

${ }^{28}$ The more energy the body produces, the more oxygen it needs, which in turn intensifies the breathing. When the breathing intensifies, it challenges the body's balance, or center of gravity control. Training exists, then, not only to develop these capacities independently, but also to deepen their interrelation. The more we are able to fluidly expand the process of producing energy, taking in oxygen and controlling our center of gravity, the more variety of movement becomes available to us, which in turn increases the stability and stability of life. Essentially the same principle can be applied to acting onstage. (Tradução nossa) 


\section{Corpo invisível, stilness e ficção}

Não são poucos os questionamentos e epifanias que podem ser despertados no decorrer de um treinamento de uma hora e trinta minutos de duração. Assim como o acesso ao corpo invisível, o método Suzuki questiona o desejo e a responsabilidade de se estar em cena. Contudo, uma vez que o treinamento é a simulação do que lidamos em cena - uma manipulação do corpo invisível -, o tempo todo se é cobrado a manter o senso de ficção. Mas o que isso significa? Imaginar, enquanto treinam, que se é uma personagem ali? Realizar o exercício "Basic \#1" como se fosse a Lady Macbeth?

Tadashi Suzuki explica:

Quando dizemos "ficção" no teatro, queremos dizer que o público sente a presença de algo se comportando como se algo realmente existisse. Essa é a diferença entre o Teatro e a cerimônia ou ritual religioso. A energia que emana de uma cerimônia [ritual] pode ser descrita como o espírito de pessoas que acreditam na existência real de esse algo, como missionários engajados no ato de proselitismo. A energia do teatro, no entanto, emana de uma situação na qual as pessoas acreditam de forma apenas condicional; ele brinca com a ideia de que algo existe, fingindo que o faz através de uma espécie de paródia. Se a religião é historicamente um fenômeno inconsciente, então o teatro é deliberado e consciente (Suzuki; Steele, 2015, p.2). ${ }^{29}$

É no chamado stilness ou estado de permanência que o corpo, durante o treinamento, consegue maximizar sua autopercepção e a percepção das condições necessárias para catalisar o senso de presença, via energia animal. Stilness ou estado de permanência é a ativação do centro de gravidade combinada a controle respiratório, engajados com o senso de energia animal, resultando, na filosofia de Tadashi Suzuki, naquilo que chamamos de presença física ou presença cênica do ator. O estado de permanência, com energia latente emanando do

${ }^{29}$ When we say "fiction" in the theater, we mean making the audience sense the presence of something by behaving as if this something really existed. This is the difference between theater and a religious ceremony of ritual. The energy that emanates from a ceremony can be described as the spirit of people who believe in the actual existence of something, like missionaries engaged in the act of proselytizing. The energy of the theater, however, emanates from a situation where people believe only conditionally; it plays with the idea that something exists by pretending that it does through a kind of parody. If religion is historically an unconscious phenomenon, then theater is a deliberate and conscious one. (Tradução nossa) 
centro de gravidade do corpo do ator/da atriz para a plateia, é constituído, em todo tempo do espetáculo, por sua presença em troca com o público. Saber iniciar esse primeiro contato do corpo com o espaço demanda treino.

Ellen Lauren, atriz da SITI Company de Nova York e mestra no método Suzuki, em artigo publicado na revista American Theater questiona o que acontece com o corpo e a voz do ator quando este é colocado na situação de ser visto enquanto tenta convencer alguém de alguma coisa. Dentre as consequências de estar em uma situação de extrema exposição, torna-se impossível conter o ímpeto de mover-se. A respiração se torna superficial, há um aumento de tensão muscular, a concentração é deturpada. Como, então, solucionar esse comportamento, segundo Ellen Lauren, universal? Como se tornar mais apto a enfrentar as tensões próprias de se estar em cena?

A resposta é: praticando stilness [estado de permanência], que é a arte da sedução. Uma vez que o ator consegue tomar decisões claras em seu corpo, sua concentração excita o espaço, e o público experimenta algo além do cotidiano, algo que transcende o cotidiano. O que está se movendo dentro de você torna-se manifesto. É uma revelação profundamente pessoal e íntima de si mesmo. Stilness permite que a força de suas convicções se torne visível. Os princípios básicos do treinamento da Suzuki são úteis para todos os atores: Esteja imóvel no palco. Risco de compromisso com a quietude. É bom para você e melhor para o público. Estabilize seu centro de gravidade como se estivesse freando contra alguma força, de modo que a imobilidade nasça do direcionamento da energia para a frente contra alguma resistência fictícia. Tanto o problema quanto a solução são autogerados. Traga consciência para seus pés e pernas. [...] Stilness [estado de permanência] fornece uma estrutura, um ponto de referência para o evento (Lauren, 2011, p.63). ${ }^{30}$

Assim, o problema se apresenta em conjunto com sua solução: através da prática de treinamento, é oferecida a oportunidade de colocar-se em situações corpóreas limítrofes, que projetam a caótica situação corporal de se estar em

\footnotetext{
30 The answer is: by practicing stillness, which is the art of seduction. Once the actor is able to make clear decisions in the body, his or her concentration excites the space, and the audience experiences something beyond the quotidian, something that transcends daily life. What is moving inside you is made manifest. It is a deeply personal and intimate revelation of the self. Stillness allows the strength of your convictions to become visible. The basic tenets of Suzuki training are helpful for all actors: Be still on stage. Risk commitment to stillness. It is good for you and better for the audience. Stabilize your center of gravity as if braking against some force, so that the stillness is born of directing energy forward against some fictional resistance. Both the problem and the solution are self-generated. Bring consciousness to your feet and legs [...] Stillness provides a structure, a reference point for the even". (Tradução nossa)
} 
cena. Através do treinamento, cria-se intimidade com as relações de tensões próprias do estado de performance, e mais apto o artista estará para captar a atenção do público e transmitir a ele seu ponto de vista.

Goto, em seu artigo "A fusão teatral de Tadashi Suzuki”, ${ }^{11}$ explica a natureza metafísica entre o estado de permanência ou stilness, e a performance a partir de Kunio Komparu. Na obra Trojan Women (As troianas), do diretor Tadashi Suzuki, há uma personagem que é o deus Budista Jizô, que entra lentamente deslizando os pés ao se mover, em um tipo de caminhada própria ao teatro Nô chamada suriashi. Após essa caminhada lenta, a personagem permanece imóvel no palco durante todo o restante da hora e meia de peça.

Goto alerta ainda que, apesar da imobilidade da personagem, ela não significa um relaxamento para o ator. Komparu, por sua vez, explica que tal habilidade de quietude exige do ator grande concentração física e mental, já que ele deve dançar "apenas com o seu coração, indo além para alcançar uma expressão do infinito" (Komparu, 1983, p. 41 apud Goto, 1989, p.115). ${ }^{32}$

Fueda Uichirô tem apresentado o papel de Jizô em inúmeras apresentações. Nós podemos encontrar um paralelo com a fala de Komparu em como Fueda se preparou para performar a divindade. "Uma forma que busquei concentração foi apontando o foco da minha visão na distância mais longe possível. Nessa distância atemporal, eu imagino apenas uma partícula de luz flutuando como se fosse do olho de uma agulha. Eu posso até chamar esse feixe de luz como uma espécie de Karma (Deus)... Concentrar-me dessa maneira me deu a sensação de que a própria consciência do meu corpo e suas sensações internas estavam afiadas a uma fina borda de brilho e pureza, como uma espada. Essa imagem de distância era mais do que uma distância física. Era um distanciamento remoto, situado como uma questão conceitual. O foco era para uma noção de Deus, de luz... Eu mantive o meu olhar fixo em uma atitude transcendental neste único ponto à distância apesar de outras realidades (as mortes e o estupro contado na peça) que me cercavam enquanto eu ficava parado lá" (Hoff, 1984, p. 107 apud Goto, 1989, p.115). ${ }^{33}$

${ }^{31}$ Originalmente denominado "The Theatrical Fusion of Suzuki Tadashi". (Tradução nossa)

${ }^{32}$ only with his heart, going beyond the visual to attain infinite expression. (Tradução nossa)

${ }^{33}$ Fueda Uichirô has played the role of Jizô in numerous performances. We can find an idea parallel to Komparu's view on the iguse in Fukuda's account of how he prepared and performed the deity: 'One way I aimed to obtain concentration was to place as far away as pos- sible the distant point that was the focus of my vision. In this timeless dis- tance I imagined a single speck of light flowing as though from the eye of 


\section{Considerações finais}

Tadashi Suzuki, em masterclass ministrada em 2015 durante o programa de treinamento oferecido pela companhia em Toga-mura, questionou e inspirou seus alunos com a provocação: “Qual a sua metáfora?”. Para além do processo de treinamento por ele desenvolvido, observa-se que, ao longo de sessenta anos de carreira, o artista trabalhou e trabalha para que sua metáfora se manifeste em todos os níveis que compõem o processo criativo cênico: desde a infraestrutura e a localidade de seu trabalho, até a criação de um método de treinamento que garanta o preparo físico e expressivo de seus atores para o cumprimento de sua visão cênica. Sua relevância para o teatro contemporâneo japonês é mundialmente reconhecida pelo seu esforço bem-sucedido em trazer para o contexto do teatro contemporâneo aspectos e valores técnicos e estéticos próprios dos teatros tradicionais Nô e Kabuki para o teatro contemporâneo.

Em 1966, aos 27 anos de idade, Tadashi Suzuki declarou: "Eu quero ter as minhas formas e palavras próprias". Desafiando a estética vigente, a Shingeki, Suzuki rompeu com seu próprio e longo processo de negação dos princípios dos teatros tradicionais Nô e Kabuki, resgatando seu potencial expressivo através do comprometimento corporal do ator e combinando elementos do teatro ocidental, como a tragédia grega, criando, assim, um discurso próprio, levando a cabo suas conviç̧ões políticas e artísticas e construindo um complexo de produção teatral no interior do Japão, em Toga-mura, Toyama.

São admiráveis a extensão e a complexidade da estética criada pelo diretor japonês, compreendendo que o método de treinamento por ele elaborado está, antes de mais nada, a serviço de um projeto artístico muito maior que a criação de um treinamento a ser difundido por todo o mundo. Antes, é a construção de um vocabulário comum com um grupo de artistas para se performar dentro de uma ideia própria do que é teatro e de sua identidade cultural, em um país oriental

a needle. I might even call this beam of light a sort of kami (god)... Concentrated in this way, I had the feeling that my own awareness of my body and its internal sensations were sharpened to a fine edge of brilliance and purity like a sword. The image of distance was more than that of physical distance. It was an infinite remoteness, positioned as a conceptual matter. The focus was the notion of God, of light... I [kept] my gaze riveted in a transcendent attitude upon this single point at a distance despite other realities (the deaths and rape recounted in the play) that surrounded me as I stood there". (Tradução nossa) 
fortemente atravessado pelo Ocidente.

Por fim, concluímos este artigo com a perpetuação, ao leitor, do questionamento: Qual a sua metáfora?

\section{Referências}

BEEMAN, W. O.; KADOGAMI, K.; SUZUKI, T. The Word is an Act of the Body. Performing Arts Journal, v. 6, n. 2, p.88-92, 15 out. 1981.

BRANDÃO, Luciana do Espírito Santo. 267 f. Os métodos Viewpoints e Suzuki em interface à composição visual. Dissertação (Mestrado em Artes da Cena) Programa de Pós-Graduação em Artes, Escola de Belas Artes, Universidade Federal de Minas Gerais, Belo Horizonte, 2018.

GIROUX, S. M. Zeami: cena e pensamento Nô. São Paulo: Editora Perspectiva, 1991.

GOTO, Y. Suzuki Tadashi: Innovator of contemporary Japanese Theater. Tese (Doutorado em Filosofia, Drama e Teatro) - University of Hawaii, Havaí, 1988.

GOTO, Y. The Theatrical Fusion of Suzuki Tadashi. Asian Theatre Journal, v. 6, n. 2, p.103-123, outono 1989. Disponível em: <http://links.jstor.org/sici?sici=07425457\%28198923\%296\%3A2\%3C103\%3ATTFOST\%3E2.0.CO\%3B2-R> .

Acesso em: 4 ago. 2021.

LAUREN, E. In Search of Stillness: Capturing the Purity and Energy of not Moving is the Root of the Invisible Body. American Theater, Nova York, v. 28, p. 62-63, 11 jan. 2011. Disponível em: <http://www.skidmore.edu/summertheater/documents/ InSearchofStillnessbyEllenLaurenAmericanTheaterJan2011.pdf>.

Acesso em: 13 maio 2017.

SUZUKI, Tadashi. The Way of Acting: The Theatre Writings of Tadashi Suzuki. Tradução de J. Thomas Rimer. Nova York: Theatre Communications Group (TCG), 1986.

SUZUKI, T.; STEELE, K. H. Culture is the Body: The writings of Tadashi Suzuki. Tradução de Kameron H. Steele. Nova York: Theater Communications Group, 2015.

SUZUKI TADASHI/Suzuki Company of Toga. 2021. Disponível em: <https://www.scot-suzukicompany.com/en/>. Acesso em: 4 ago. 2021.

SUZUKI TADASHI/Suzuki Company of Toga. [s.l.]. Disponível em: <https://www.scot-suzukicompany.com/en/>. Acesso em: 4 ago. 2021. 
Recebido em: 15/08/2021

Aprovado em: 23/11/2021

Universidade do Estado de Santa Catarina - UDESC

Programa de Pós-Graduação em Teatro - PPGT

Centro de Arte - CEART

Urdimento - Revista de Estudos em Artes Cênicas

Urdimento.ceart@udesc.br 